\title{
Pacto Nacional pelo Fortalecimento do Ensino Médio - PNEM: a formação continuada na Gered de Chapecó - SC*
}

Sandra Maria Zardo Morescho ${ }^{a}$ Nadir Castilho Delizoicov ${ }^{b}$

\section{Resumo}

Este artigo apresenta dados sobre a formação continuada de professores ofertada pelo Pacto Nacional pelo Fortalecimento do Ensino Médio (PNEM) no período de 2014 a 2015. O trabalho teve como objetivo investigar as percepções dos orientadores de estudo do Pacto sobre a formação desenvolvida junto a professores de 10 escolas públicas estaduais pertencentes à Gerência Regional de Educação (Gered) de Chapecó, Oeste de Santa Catarina. Os dados foram obtidos através de entrevistas semiestruturada e suas análises apresentam o parecer do orientador de estudo, as mudanças nas ações dos professores e os impactos do término do PNEM. Os resultados indicaram que a formação foi de significativa qualidade, induzindo ao reconhecimento do estudante em sua individualidade. Como aspecto negativo, encontra-se a finalização do PNEM, bem como o temor do aumento da desvalorização da docência diante da Reforma do Ensino Médio.

Palavras-chave: PNEM. Orientador de Estudo. Formação continuada.

\section{Introdução}

Apresentamos neste artigo resultados de uma pesquisa sobre o processo de formação continuada de professores, ofertado por meio do Pacto Nacional pelo Fortalecimento do Ensino Médio (PNEM), durante os anos de 2014 e 2015. A investigação envolveu orientadores de estudo que mediaram a formação nas escolas públicas da Rede Estadual de Ensino, pertencentes à Gerência Regional de Educação (Gered) de Chapecó, SC. O problema de pesquisa foi assim formulado:

\footnotetext{
* Pesquisa financiada pela Coordenação de Aperfeiçoamento de Pessoal de Nível Superior e pela Fundação de Amparo à Pesquisa e Inovação do Estado de Santa Catarina.

a Universidade de Passo Fundo, Passo Fundo, RS, Brasil.

b Universidade Comunitária da Região de Chapecó, Chapecó, SC, Brasil.
} 
qual o parecer dos orientadores de estudo sobre o PNEM? Buscou-se identificar, ainda, as mudanças observadas nas escolas nas quais a formação foi realizada, bem como os impactos do término do programa e da instituição da Reforma do Ensino Médio, ocorridos durante o desenvolvimento da pesquisa.

O texto está, assim, organizado: primeiramente, encontra-se uma discussão sobre a formação inicial do professor para o exercício da docência e a necessidade da formação permanente, ao longo da carreira, assegurada por políticas públicas. Na sequência, apresentamos a formação ofertada pelo PNEM, seus objetivos e o papel do orientador de estudo no processo de mediação junto aos professores. Em seguida, encontram-se a descrição da metodologia utilizada para a pesquisa e a análise dos dados. Finalmente, estão as considerações sobre a pesquisa realizada, seguidas das referências que subsidiaram a elaboração deste trabalho.

\section{Formação permanente: uma caminhada necessária}

Assumir o compromisso da docência exige saberes e responsabilidades, objetivando disseminar conhecimentos socialmente construídos e formar estudantes críticos e capazes de atuar na sociedade, visando às transformações.

Para tanto, a atuação docente alicerça-se na formação inicial que "[...] cria as bases sobre as quais esse profissional vem a ter condições de exercer a atividade educativa na escola com crianças e jovens que aí adentram, como também, as bases de sua profissionalidade e da constituição de sua profissionalização" (GATTI; BARRETO; ANDRÉ, 2011, p. 89). Por outro lado, deve-se considerar que a atuação docente requer "[...] processos de aprender a ensinar e de aprender a profissão, ou seja, de aprender a ser professor, de aprender o trabalho docente, são processos de longa duração e sem um estágio final estabelecido a priori” (MIZUKAMI, 1996, p. 64).

A formação continuada deve contribuir, principalmente, para a reflexão sobre o fazer pedagógico, para a troca de experiências entre os profissionais, e, ainda, ser reconhecida como um direito e uma necessidade para os professores inseridos nos sistemas de ensino (ARAÚJO; ARAÚJO; SILVA, 2015). Assim, a formação continuada constitui-se num movimento orientado ao longo da carreira, associado ao desenvolvimento profissional docente, com a finalidade de discutir e buscar alternativas para os desafios que se apresentam nas diferentes fases da vida profissional. 
Para Alvaro-Prada, Freitas e Freitas (2010), a formação humana e a formação continuada de professores são processos muito semelhantes. Os autores defendem que a formação humana ocorre toda a vida, decorrente do constante processo de humanização vivido por homens e mulheres que interagem e se relacionam com outros sujeitos, ação, a partir da qual aprendem, tornando esse aprendizado parte de si. Em relação à formação docente, os autores argumentam que "[...] é uma contínua caminhada dos profissionais da educação, em cujo caminhar atuam em todas as suas dimensões individuais e coletivas de caráter histórico, biopsicossocial, político, cultural, próprias de seres integrais e autores de sua própria formação" (ALVARO-PRADA; FREITAS; FREITAS, 2010, p. 370). Nesse sentido, para Freire (1996), o ser humano é um ser inacabado, uma vez que a formação humana ocorre nas diferentes fases e idades da vida do sujeito.

Assim, a condição de ser inacabado é também identificada na formação do professor, condição essa que se manifesta através da reflexão do sujeito. "O homem pode refletir sobre si mesmo e colocar-se num determinado momento, numa certa realidade: é um ser na busca constante de ser mais e, como pode fazer esta autorreflexão, pode descobrir-se como um ser inacabado, que está em constante busca" (FREIRE, 1979, p. 27).

Reconhecida tal condição do ser humano e a necessidade de a formação do professor ser contínua, Silva e Araújo $(2005$, p. 2) apresentam quatro momentos básicos que devem balizar o processo de formação continuada, sendo eles "[...] o conhecimento na ação; a reflexão na ação; a reflexão sobre a ação; e a reflexão para a ação. Aqui se entende por ação toda a atividade profissional do professor". Ao sinalizarem os processos de reflexão sobre a ação e a reflexão para a ação, os autores buscam apoio em Freire (1996, p. 38), o qual destaca a importância de uma prática docente crítica, em que o "pensar certo" estabelece um movimento dinâmico e dialético, entre a ação e o pensar sobre a ação. Nesse sentido, é desejável que a prática pedagógica seja orientada pela reflexão crítica, pelo ato de "pensar certo", considerando a realidade em que o estudante, o professor e a escola estão inseridos.

O "pensar certo" para Freire (1996) caracteriza-se pela avaliação e reavaliação das experiências vivenciadas, para que, a partir delas, sejam planejadas as próximas intervenções, considerando os conhecimentos e as experiências do professor. "Por isso é que, na formação permanente dos professores, o momento fundamental é o da reflexão crítica sobre a prática. É pensando criticamente a prática de hoje ou de ontem que se pode melhorar a próxima prática" (FREIRE, 1996, p. 39). 
O aprendizado do professor se dá constantemente, bem como a reflexão na ação, sobre a ação e a reflexão para a ação, permitindo que os saberes se modifiquem e que a experiência se transforme.

A formação continuada é concebida como um processo contínuo e permanente de desenvolvimento profissional do professor, onde a formação inicial e continuada é concebida de forma interarticulada, em que a primeira corresponde ao período de aprendizado nas instituições formadoras e a segunda diz respeito à aprendizagem dos professores que estejam no exercício da profissão mediante ações dentro e fora das escolas (SILVA; ARAÚJO, 2005, p. 5).

A consciência da necessidade de uma formação permanente, provoca o educador a aproximar-se "[...] da natureza do ser que é capaz de se comprometer [...]" (FREIRE, 1979, p. 16), direcionando-o para um ato de comprometimento com a busca constante da formação, revelando seu vínculo com a educação, o que só é possível através de sua ação e reflexão.

Na sequência, apresentamos aspectos da formação ofertada pelo PNEM e descrevemos o papel do orientador de estudo nesse processo formativo.

\section{A formação continuada e o orientador de estudo}

Tratando-se da formação do professor, Gatti e Barreto (2009) destacam a importância da inclusão dos conhecimentos adquiridos na formação da prática docente, bem como a importância de políticas públicas direcionadas à formação continuada de professores. De acordo com as autoras, a formação continuada passou a ser reconhecida com a promulgação da Lei de Diretrizes e Bases da Educação Nacional, Lei no 9.394/96, que estipula, em seu Artigo 67, que:

Os sistemas de ensino promoverão a valorização dos profissionais da educação, assegurando-lhes, inclusive nos termos dos estatutos e dos planos de carreira do magistério público [...] aperfeiçoamento profissional continuado, inclusive com licenciamento periódico remunerado para esse fim (BRASIL, 1996, [s. p.]).

Tão importante quanto as políticas direcionadas à formação continuada, destaca-se a relevância dos estudos e pesquisas desenvolvidos nessa área, especialmente ao investigar os processos formativos, analisando suas potencialidades e fragilidades, 
bem como podem ser responsáveis em reafirmar a pertinência da formação permanente ao longo da profissão docente.

O PNEM, além de representar a articulação e a coordenação de ações e estratégias entre a União e os governos estaduais e distrital na elaboração e implementação de políticas, visando a elevar o padrão de qualidade do ensino médio brasileiro, teve como objetivo a valorização da formação continuada dos professores e coordenadores pedagógicos do ensino médio de escolas públicas. O programa, instituído através da Portaria $n^{\circ} 1.140$, de 22 de novembro de 2013, em parceria com o Ministério da Educação (MEC) e as Secretarias Estaduais e Distrital de Educação, teve como meta rediscutir e atualizar as práticas docentes em conformidade com as Diretrizes Curriculares Nacionais do Ensino Médio (BRASIL, 2013a).

A formação ofertada pelo PNEM ocorreu nos anos de 2014 e 2015, teve como tema: "Sujeitos do Ensino Médio e Formação Humana Integral" (BRASIL, 2016a). Foi desenvolvida na modalidade presencial, nas escolas públicas estaduais $^{1}$ de atuação dos professores de ensino médio que participaram do processo, sob a coordenação do orientador de estudo. A formação somou um total de 200 horas e cada escola possuía um cronograma com datas, horários e dias da semana para a realização das atividades referentes ao PNEM, com o grupo de professores. Apesar de a Portaria $n^{\circ}$ 1.140/2013 recomendar a formação dentro da carga horária dos docentes, os orientadores de estudo se depararam com a dificuldade em conciliar os dias e horários, pois muitos professores trabalhavam em mais de uma escola, além daquela em que a formação era ofertada. Esse fato fez com que algumas escolas realizassem a formação nos intervalos entre os turnos vespertino e noturno e, em outras, o PNEM teve que ser realizado aos sábados.

Na primeira etapa do PNEM, realizada em 2014, foram estudados os cadernos que contemplavam os seguintes temas: Ensino médio e formação humana integral; O jovem como sujeito do ensino médio; Currículo do ensino médio, seus sujeitos e o desafio da formação humana integral; Áreas de conhecimento e integração curricular; Organização e gestão democrática da escola; Avaliação no ensino médio. A formação teve continuidade no ano de 2015, sendo direcionada à Organização do trabalho pedagógico no ensino médio e para as áreas do conhecimento: Ciências Humanas, Ciências da Natureza, Linguagens e Matemática.

\footnotetext{
1 Por motivo de sigilo, não foi revelado, neste trabalho, o nome das escolas, informação restrita ao pesquisador.
} 
A leitura, a reflexão e a discussão dos cadernos de estudos seguiram as propostas das Diretrizes Curriculares Nacionais do Ensino Médio (DCNEM), as quais recomendam que os professores compreendam a totalidade dos componentes curriculares para o desenvolvimento de novas possibilidades de organização do conhecimento escolar e a ampliação das possibilidades de integração entre as diferentes áreas do conhecimento (BRASIL, 2014). Tendo como proposta a formação integral do indivíduo, o PNEM evidenciou a importância de reconhecer o estudante do ensino médio como sujeito que possui conhecimentos e interesses, para assim relacioná-los aos conteúdos trabalhados.

Os orientadores de estudo foram os responsáveis pela mediação da formação ofertada aos professores do ensino médio, atendendo aos requisitos da Portaria $\mathrm{n}^{\mathrm{o}}$ 1.140/2013 (BRASIL, 2013a). O orientador de estudo deveria ser professor ou coordenador pedagógico do ensino médio, do quadro efetivo do magistério da Rede Pública Estadual de Ensino. A portaria determinava, ainda, que o profissional deveria ser formado em Pedagogia ou outra licenciatura, ter atuado, no mínimo, três anos no ensino médio como professor ou coordenador pedagógico e/ou possuir experiência comprovada na formação de professores para esse nível de ensino, ter disponibilidade de 20 horas semanais para dedicar-se à formação e aos encontros com o formador regional, bem como disponibilidade para o trabalho junto aos professores/coordenadores do ensino médio (BRASIL, 2013a).

O município de Chapecó, localizado na região oeste do estado de Santa Catarina, constituiu a área de abrangência para a realização desse estudo. Nele localizamse a Gered, que representa a rede estadual de ensino de Santa Catarina, e a Universidade a qual esta pesquisa esteve vinculada, no âmbito do Mestrado em Educação, entre os anos de 2015 e 2017. Pressupõe-se que devido ao curto período (2014-2015) de execução do PNEM, não foram observados na literatura estudos relacionados sobre a percepção e/ou à avaliação do profissional foco deste trabalho, na área delimitada. Destaca-se que a pesquisa teve como objetivo verificar a percepção dos orientadores de estudo sobre o processo de formação continuada, ofertada por meio do PNEM aos professores e coordenadores pedagógicos do ensino médio de escolas públicas, pertencentes à Gered de Chapecó/SC.

Na próxima seção, são apresentados dados correspondentes à percepção dos orientadores de estudo da Gered de Chapecó, em relação ao processo formativo ofertado pelo PNEM. 


\subsection{Apresentação e análise dos dados}

É importante destacar, ainda, que a pesquisa realizada se deu a partir das percepções do orientador de estudo, um profissional da própria escola, que mediou a formação ao grupo de professores, ou seja, aos seus pares. Vale ressaltar que, durante os processos formativos, é comum a presença de profissionais das Instituições de Ensino Superior (IES) mediarem a formação dos professores da educação básica. O PNEM constituiu-se em uma exceção, pois a mediação ocorreu pelo próprio profissional da unidade escolar.

Com o intuito de localizar orientadores de estudo para colaborarem com a pesquisa, foram selecionadas dez escolas entre as vinte e oito que ofertam o ensino médio em Chapecó. O critério para a seleção baseou-se nas escolas que tinham o maior número de professores participando da formação, conforme informações fornecidas pela Gered. Obteve-se, assim, um total de doze orientadores de estudo, uma vez que, em duas escolas, devido ao número de professores, aproximadamente quarenta sujeitos, a formação foi mediada por dois orientadores de estudo. Os dados para a análise foram gerados a partir de entrevistas semiestruturadas, realizadas individualmente com os orientadores selecionados, em suas respectivas escolas, destacando-se que as mesmas foram gravadas, transcritas e analisadas.

Os orientadores de estudo entrevistados são efetivos em escolas de ensino médio da Rede Estadual de Ensino, trabalham 40 horas/aulas semanais; as funções que desempenham variam entre orientador educacional, assistente de educação, assistente técnico-pedagógico e professor; o tempo de serviço compreende entre 10 e 32 anos; todos possuem licenciatura plena, seguida de especialização; dois entrevistados possuem mestrado, um em educação, e outro, em história. Os dados obtidos tiveram Bardin (1979) como base para a análise. Para esse trabalho, foram eleitas três categorias de análise (LUNA, 1997): a) parecer do orientador de estudo; b) mudanças observadas; c) término do PNEM, sendo que cada uma delas é discutida numa sessão.

A primeira sessão corresponde o parecer do orientador de estudo, que reconheceu a relevância da formação, a qual, além de ter sido direcionada aos docentes do ensino médio, algo que na época não era comum, reconheceu o estudante desse nível de ensino como sujeito na perspectiva de uma formação humana integral.

A sessão seguinte aborda as mudanças observadas após a realização do PNEM, como o fortalecimento do grupo de professores, desenvolvimento de práticas e projetos interdisciplinares, a implementação de novas metodologias e mudanças 
na avaliação, a qual, além da aprendizagem, passa a considerar o estudante do ensino médio na sua individualidade.

E, finalizando a análise dos dados, discutem-se mudanças políticas em nível nacional ocorridas no ano de 2016, como a sanção da Medida Provisória ${ }^{\circ}$ 746 (BRASIL, 2016b), seguida da aprovação da Lei no 13.415/2017 (BRASIL, 2017), no ano de 2017, que instituiu a Reforma do Ensino Médio, confirmando o término do PNEM.

\subsection{O parecer do orientador de estudo}

A partir da análise dos resultados da pesquisa, foi possível observar que os orientadores de estudo consideraram que a formação ofertada aos professores do ensino médio, por meio do PNEM, foi de grande relevância. Entre os aspectos positivos, destacaram a importância dos temas e dos conteúdos presentes nos cadernos do PNEM, os quais permitiram relacionar as temáticas à realidade que envolvia a escola naquele momento, bem como a troca de experiências entre os docentes das diferentes áreas do conhecimento. "Essa formação foi muito boa. Esse nível de formação deveria ser dado todo o ano ou ter uma sequência. Isso, pra mim, é formação continuada" (OE10)².

Os orientadores destacaram, ainda, a importância dos temas e conteúdos presentes nos cadernos, considerando o estudante desse nível de ensino como sujeito na perspectiva de uma formação humana integral. Os comentários expressam a qualidade do material utilizado durante a formação, que permitiu a leitura, estudo e discussão no grupo de professores de cada escola: "O PNEM teve muita referência no grupo de professores. Os assuntos e conteúdos eram relevantes, levávamos para as reuniões pedagógicas, para as paradas pedagógicas" (OE7). Na medida em que eram realizados os estudos das temáticas presentes nos cadernos do PNEM, os orientadores de estudo observaram que estas tinham relação com a realidade vivenciada nas escolas:

O PNEM foi importantíssimo no sentido de permitir discutir os reais problemas que tínhamos dentro da escola. Enquanto a gente estudava os textos dos cadernos, [...] percebíamos uma clara relação daqueles problemas e sugestões de trabalho para nossa realidade escolar (OE9).

Durante a apresentação e análise dos dados, a sigla OE - orientador de estudo, seguida de números de acordo com a ordem de gravação das entrevistas, será utilizada para identificar os orientadores de estudo que colaboraram com a pesquisa, garantindo assim seu anonimato. 
Um dos fatores que evidencia a importância do PNEM foi por tratar-se de uma formação organizada especialmente dos docentes do ensino médio, pois, geralmente, os processos de formação continuada voltam-se aos professores do ensino fundamental. O reconhecimento da relevância da formação do professor e, consequentemente, para o estudante foi observada no depoimento dos orientadores de estudo: "Penso que o PNEM foi uma oportunidade para os professores estarem se atualizando um pouco, conhecendo e desenvolvendo um novo olhar em relação ao aluno, em relação às formas de aprendizagem e ensino" (OE6); "[...] na nossa escola, os professores mostravam o prazer e a valorização por essa capacitação. Não se encontrava mais capacitação com esse nível há muito tempo, principalmente para o ensino médio" (OE7).

Os encontros do orientador de estudo com os professores ocorreram numa dinâmica que proporcionou maior aproximação entre os docentes, bem como o trabalho coletivo, não apenas para estudar, discutir os textos e os problemas existentes no espaço escolar, mas para planejar estratégias que, posteriormente, foram desenvolvidas na prática, por meio de atividades interdisciplinares: “[...] foi através do PNEM que se começou a pensar nos primeiros passos da formação humana integral, da escola integral, do trabalho por áreas do conhecimento, que, até este momento, percebo como ponto positivo em nossa escola" (OE12); "A partir do PNEM, nós começamos a organizar trabalhos interdisciplinares [...], trocando experiências, trocando ideias" (OE11).

As atividades interdisciplinares planejadas pelos professores contribuíram para a aproximação entre eles, num trabalho coletivo. "Então eu penso que possibilitou toda essa questão do diálogo encontrando estratégias, unindo o grupo, criando uma identidade para o ensino médio" (OE1).

Uma das temáticas presentes nos cadernos do PNEM referia-se à formação humana integral do jovem do ensino médio, que agregasse aspectos científicos, humanísticos e culturais à aprendizagem "[...] a formação humana integral implica competência técnica e compromisso ético, que se revelem em uma atuação profissional pautada pelas transformações sociais, políticas e culturais necessárias à edificação de uma sociedade igualitária" (BRASIL, 2013b, p. 34). Nessa perspectiva, a formação do estudante deve contemplar as dimensões "[...] intelectual, afetiva, social, corpórea, com vistas a propiciar um itinerário formativo que potencialize o desenvolvimento humano em sua plenitude, que se realiza pelo desenvolvimento da autonomia intelectual e moral" (BRASIL, 2013c, p. 32). Nesse sentido, os estudos permitiram ao grupo de professores ampliar a noção de formação humana para além da aprendizagem, reconhecendo 
o estudante como um sujeito envolvido em outras relações além da escola e que seu percurso formativo se dá ao longo da vida:

[...] teve coisas que vieram com o PNEM e foram muito positivas [...] a formação desse indivíduo, desse estudante, a formação integral, compreender o que é você formar o indivíduo [...]. O PNEM fortaleceu a questão de você interiorizar que o sujeito tem uma caminhada, traz em seu bojo uma história, que precisa ser compartilhada, falada. É esse o outro olhar como sujeito histórico que está aí. Cada um tem seu trajeto, sua caminhada e cada um tem seu percurso formativo [...] (OE8).

O envolvimento dos docentes foi considerado, pelos orientadores de estudo, como positivo: "A maioria dos professores abraçou a causa, tinha a necessidade e a vontade de estudar e pensar numa reformulação de como ensinar a esse sujeito que está no ensino médio" (OE8).

Diante do exposto, observa-se a necessidade de o professor realizar a formação para compreender melhor o estudante do ensino médio e melhorar o seu fazer pedagógico. Além de contar com os docentes das diversas áreas do conhecimento, realizando um trabalho que envolvia a interdisciplinaridade, o orientador de estudo procurou desempenhar seu papel atendendo às necessidades do grupo, bem como buscou avaliar os momentos de estudo para potencializar cada vez mais a formação

O grupo de professores era muito bom. Tinha professores de todas as áreas, tinha interdisciplinaridade [...] eu sempre conversava com o grupo para fazer um trabalho legal, que eles gostassem e sempre procurava avaliar no final o que eles tinham achado, se estava bom ou tinha que modificar [...] a gente sentava para estudar mesmo (OE4).

O envolvimento dos professores durante o PNEM permitiu, além do estudo, reflexão, debates, trocas de experiências e planejamento, a execução de atividades com os estudantes, o que resultou, a partir dos relatos das experiências, na publicação de artigos no Caderno Regional do PNEM (BRASIL, 2015), correspondente à Gered de Chapecó. Para os orientadores de estudo, o programa de formação continuada permitiu o estudo e a reflexão entre a teoria e a prática "[...] foi um programa fantástico que movimentou a escola, reuniu os professores [...] Então, me pareceu que o grupo esteve mais unido, pois tinha esse tempo, semanalmente, para se encontrar e discutir, tanto a parte teórica como a prática $[\ldots] "(\mathrm{OE} 1)$. 
A partir dos relatos positivos da formação, tanto para o professor quanto para os estudantes, os orientadores de estudo destacaram importantes mudanças que influenciaram diretamente no fazer pedagógico nas escolas nas quais o PNEM foi realizado, como se pode observar em seguida.

\subsection{Mudanças observadas}

De acordo com os orientadores de estudo, a formação pelo PNEM contribuiu significativamente para mudanças no trabalho pedagógico. Práticas interdisciplinares foram incrementadas, a avaliação passou a ser realizada sob uma visão mais humana do estudante do ensino médio, o relacionamento entre os professores tornou-se mais cooperativo, pois por decisão deles próprios, reuniam-se com antecedência para preparem as discussões. "Penso que o PNEM ajudou bastante, porque o coletivo melhorou muito [...]" (OE5).

Ao trocar informações com seus pares, o professor se permite realizar um trabalho conjunto, pois mesmo sendo de diferentes componentes curriculares é possível planejar e avaliar as possibilidades de um trabalho que possa minimizar a fragmentação do conhecimento, o que pode contribuir para a apropriação de conceitos pelo aluno "[...] era um momento que proporcionava o diálogo, onde o professor conseguia trocar algumas informações com os demais para saberem o que estariam trabalhando e o que poderiam trabalhar juntos" (OE1).

Esse movimento consolida-se através da interdisciplinaridade, mencionada nos comentários dos orientadores de estudo: "A maioria conseguiu captar esse novo olhar, adaptar de maneira diferente suas metodologias [...] através da interdisciplinaridade" (OE8); "O que melhorou foi o trabalho das áreas do conhecimento [...] vejo que fomos direcionados [...] o professor creio que hoje está consciente e tem essa clareza que o trabalho deve ser por área de conhecimento" (OE10).

O trabalho realizado entre as disciplinas das áreas do conhecimento contribuiu para o desenvolvimento de projetos de ensino interdisciplinares, que proporcionaram resultados expressivos. Mesmo com o término do PNEM, muitos desses projetos continuaram sendo realizados.

A partir do PNEM, começamos a determinar que um grupo de professores faria uma atividade. Já o outro grupo faria outra atividade. Percebemos que com o grupo reduzido de professores envolvidos, o acompanhamento das atividades, os registros, seria facilitado, obtendo melhores resultados. A partir daí, dividimos a responsabilidade com os nossos professores [...]. Hoje temos vários 
projetos na escola e cada um deles é pensado, escrito e organizado por um grupo de professores [...] cada um vai se encaixando naquele que tem mais afinidade e faz a coisa dar certo realmente (OE9).

A recomendação do PNEM, em relação à avaliação (BRASIL, 2013d), era para que a mesma ocorresse durante o desenvolvimento do programa curricular, permitindo a revisão de estratégias e ajustes nas atividades e no planejamento, possibilitando verificar os progressos e dificuldades dos estudantes. A preocupação em adotar novas metodologias e avaliar de forma diferenciada traduz essa nova visão do estudante do ensino médio por parte dos professores, conforme observado pelos orientadores de estudo, "[...] com o PNEM houve muitas mudanças, até como os professores veem os alunos do ensino médio, [...]" (OE7).

O PNEM contribuiu para o processo de reconhecimento do estudante do ensino médio como sujeito, dentro de sua individualidade, induzindo o professor a reconhecê-lo enquanto pessoa que tem alegrias, tristezas, problemas, uma vida além da escola: "Ao longo da formação, as mudanças foram bem visíveis [...]. $\mathrm{O}$ aluno passou a ser visto com outro olhar, o professor começou a desenvolver outras atividades, ouvir o aluno de forma diferente" (OE6). De acordo com os orientadores de estudo, o estudante do ensino médio passou a participar mais efetivamente com sugestões consideradas no processo ensino e aprendizagem:

[...] a partir dos estudos do PNEM, foi visível a voz que o aluno ganhou. Ele passou a fazer parte desse grupo, das discussões, debates, expressando seus desejos, seus anseios, seus interesses vinculados à educação e passou a representar isso na sua prática, participar. Em diversos momentos os alunos passaram a ser consultados, socializando com eles algumas ideias que a escola pretendia fazer (OE6).

De modo geral, a formação ofertada pelo PNEM proporcionava a movimentação do professor e do estudante, incentivava e despertava a criatividade, instigava o surgimento de novas ideias para o trabalho docente. A partir das percepções dos orientadores de estudo, pode-se dizer que esse programa contribuiu para que os professores do ensino médio estivessem mais motivados para trabalhar de forma cooperativa com o estudante.

Diante do exposto, reafirma-se a importância e a necessidade da formação continuada, como um processo que agrega novos conhecimentos, sendo necessária ao longo de toda carreira docente visando a melhoria do ensino. 


\subsection{O término do PNEM diante da Reforma do Ensino Médio}

Finalizada a segunda etapa da formação, os profissionais envolvidos aguardavam uma terceira etapa. Porém o sentimento de esperança de continuidade foi substituído pela lamentação, expressa pelos orientadores de estudo: “[...] era um momento que se proporcionava o diálogo, entre os professores que conseguiam trocar algumas informações sobre o que trabalhavam e o que poderiam trabalhar juntos" (OE1):

A interrupção do PNEM é uma pena! Acho que esse modo de formar os professores deveria ter sempre na escola, em todos os anos letivos, terminar uma etapa e fazer outra [...] eu vejo que os professores têm necessidade, eles precisam estudar, precisam debater, precisam trocar ideias (OE7).

Reconhecer-se na condição do ser inacabado, como uma característica vital do ser humano (FREIRE, 1996) o que está claro nos depoimentos dos orientadores de estudo o reconhecimento da importância da formação continuada como momento de troca de experiências, sobretudo por dar-se no próprio ambiente de trabalho. "Precisamos ter constantemente essa formação continuada que o PNEM proporcionou [...] no sentido de poder trocar as ideias, de poder discutir, de poder sugerir, pensar estratégias coletivamente. Considero que a perda está nesse sentido" (OE9). A manifestação do desejo pela continuidade do PNEM foi unânime entre os colaboradores da pesquisa: "É o que todos dizem: que o PNEM deveria continuar. As discussões foram muito boas, momentos muito bons em que aprendemos muito, socializamo-nos, conhecemos melhor os colegas, tivemos tempo para conversar, discutir [...]" (OE4).

No entanto, com as mudanças políticas em nível nacional, observadas principalmente no segundo semestre do ano de 2016, como o impeachment da Presidenta Dilma Rousseff, seguido da aprovação da Proposta de Emenda à Constituição (PEC) do Teto dos Gastos/PEC n 55 e da imposição da Medida Provisória $n^{\circ} 746$, de 22 de setembro de 2016, observou-se, entre os orientadores de estudo, certo pessimismo em relação à continuidade do PNEM, bem como de investimentos na formação continuada de professores: “[...] mas com todas essas mudanças que estão ocorrendo hoje, eu não acredito que o PNEM continue, principalmente com os cortes que estão acontecendo" (OE5).

A confirmação do término do PNEM deu-se com a aprovação da Medida Provisória $\mathrm{n}^{\circ}$ 746, de 22 de setembro de 2016, que em 16 de fevereiro de 2017 foi convertida e aprovada na Lei $\mathrm{n}^{\circ}$ 13.415/2017, que instituiu a Reforma do Ensino Médio (BRASIL, 2017). Conforme Silva e Sheibe (2017), a Reforma do Ensino Médio 
configurou-se num processo impositivo e arbitrário, sendo uma representação legítima de que as políticas educacionais são modificadas com a alternância de governo, tendo, como base, argumentos que defendem processos de inovação e melhoria da qualidade na educação. Argumentos que, para Moura e Lima Filho (2017), foram proferidos nos discursos oficiais, que difundindo uma suposta crítica de "ineficiência e falta de flexibilidade" no ensino médio pertencente à educação básica, especificamente na rede pública de ensino, acabaram por reforçar um discurso para uma reforma realizada às pressas, anulando a possibilidade de um debate social e democrático.

Ferreira e Ramos (2018) apresentam uma análise da Lei $\mathrm{n}^{\mathrm{o}}$ 13.415/2017, destacando as principais mudanças propostas para o ensino médio, que tem como consequência uma formação do estudante direcionada para o mercado de trabalho, identificada especialmente nas mudanças curriculares propostas, que, em comparação ao ensino médio ofertado em momento anterior à aprovação da referida lei, apresentam a redução de um tempo significativo para os estudos da Base Comum Curricular. Outro quesito abordado pelas autoras refere-se aos principais desafios à concretização da nova política, considerando os investimentos financeiros necessários para a implementação de um ensino em tempo integral, com uma ampliação significativa da carga horária do estudante na escola. Entretanto, analisando a conjuntura política atual, observa-se um cenário preocupante para a educação brasileira, deflagrado nos drásticos bloqueios nos investimentos não apenas em relação ao ensino superior e à pesquisa, mas especialmente na educação básica na rede pública de ensino.

A finalização do PNEM, diante da nova política educacional, traduz a preocupação de Gatti e Barreto (2009), quando defendem a necessidade de os processos de formação continuada terem sequência mesmo com as mudanças de governo. Com a aprovação da Reforma do Ensino Médio, observa-se a implementação de uma nova política educacional, prometendo a solução dos problemas que tem afetado a educação brasileira.

Para Ferreira, Albuquerque e Windler (2017), os modelos educacionais padronizados são impostos com a justificativa de garantir a eficácia e êxito nas escolas. No entanto, o que se observa são reformas seguidas de reformas, a seguinte substituindo a anterior, comprometendo os processos de formação continuada e a profissionalidade ${ }^{3}$ do professor. Não há o reconhecimento das práticas, saberes e

Refere-se ao conjunto de conhecimentos, saberes, técnicas e competências indispensáveis à atividade profissional. Através da profissionalidade, o professor adquire os saberes próprios de sua profissão e as competências para exercer a docência (NÚÑES; RAMALHO, 2008). 
experiências de professores e estudantes os quais são reduzidos a consumidores de políticas de governo.

Com a finalização do PNEM, encerrou-se a formação continuada para o professor do ensino médio, instalou-se uma nova política sem o diálogo com a sociedade, sem considerar os estudos e pesquisas sobre a educação básica, realizadas pela comunidade acadêmica (CARRANO, 2016). Uma nova política, que alterou a Lei de Diretrizes e Bases da Educação Nacional - Lei no 9.396/1996, reconhece o notório saber, desconsiderando a formação do professor, criando possibilidades para que profissionais não licenciados ingressem no magistério. Admitir profissionais sem uma formação direcionada para a docência contribui para a desvalorização da formação de professores, para fragilizar a docência e, principalmente, compromete a qualidade do ensino ofertado (CASTILHO, 2017).

Não há a intenção de afirmar, aqui, que o conhecimento do profissional detentor do notório saber não tenha valor, mas, para o exercício da docência, o professor forma-se em um percurso específico, passando pela formação inicial e pela formação continuada ao longo da vida profissional. A desvalorização do professor acentua-se quando passa a concorrer com profissionais que, apenas comprovando seus conhecimentos em qualquer habilitação técnica, recebem o aval para exercer a docência (SILVA, 2017).

A formação do professor do ensino médio durante o PNEM caiu no esquecimento, tornando evidente o descaso e a desvalorização da formação continuada do professor para exercer a docência. Castilho (2017, [s. p.]) defende que "A formação do professor é indispensável porque há saberes e competências que são específicos da docência. Ensinar bem uma matéria não requer apenas saber o conteúdo - é preciso compreender o complexo processo ensino-aprendizagem". É preciso saber fazer, refletir sobre a ação avaliando-a constantemente, fazendo um novo planejamento sempre que necessário, trocar experiências entre os pares, reconhecer as potencialidades do estudante auxiliando-o a superar fragilidades, e isso o docente aprende ao longo de sua própria formação.

\section{Considerações finais}

Ao analisar o parecer dos orientadores de estudo foi possível observar que o PNEM teve sua importância reconhecida, com temas relevantes voltados ao percurso formativo do jovem do ensino médio na perspectiva de uma formação humana integral. A formação oportunizou momentos de estudo, reflexão, relação dos temas estudados com a prática docente, troca de experiências, bem como uma maior aproximação entre os docentes, o que contribuiu para trabalho 
coletivo. Durante o PNEM, o docente demonstrou que tem interesse em realizar a formação continuada ao longo da carreira, deseja momentos reservados para estudo e interação com os pares para reflexão de suas ações pedagógicas e troca de experiências.

Para os orientadores de estudo, o PNEM contribuiu com mudanças significativas na prática dos professores do ensino médio, que além de desenvolverem um trabalho interdisciplinar, reconheceram o estudante do ensino médio como sujeito, que se insere numa determinada realidade, que tem problemas e alegrias. Esse reconhecimento contribuiu para mudanças positivas no processo de avaliação, pois passou-se a considerar, também, o percurso formativo do estudante, numa perspectiva de formação integral do sujeito.

No entanto, mudanças políticas levaram à finalização do PNEM, com a instituição da Reforma do Ensino Médio, firmada com a aprovação da Lei n ${ }^{\circ}$ 13.415/2017. Assim, reforça-se que as políticas educacionais acabam por representar os interesses de governo, quando seria desejável que se tornassem políticas de Estado, o que asseguraria a sua continuidade.

Com o PNEM, ficou evidente que, quando há vontade política e investimentos, é possível ofertar formação docente sistematicamente organizada, dentro da carga horária do professor, com bolsa de estudo aos participantes, realizada no próprio local de trabalho, trazendo para discussão problemas da comunidade escolar.

No entanto, o que se tem para o momento é a Reforma do Ensino Médio, que fere princípios de igualdade não apenas entre os estudantes, mas entre os profissionais da educação e não valoriza a formação docente, o que compromete o princípio do direito a uma educação de qualidade para todos. 


\title{
National Pact for Strengthening High School Education: Continuing education teachers in Chapecó - SC
}

\begin{abstract}
This article presents data about the continuing education of teachers offered under the National Pact for Strengthening High School Education (PNEM), for 2014 and 2015. The objective of the study was to investigate the perceptions of the supervisors of the study of the influence of the Pact on the training offered to teachers in 10 state public schools under the Regional Educational Administration (Gered), of Chapecó in Western Santa Catarina state. The data were obtained from semistructured interviews and their analyses present the report of the supervisor of the study, the changes in the actions of the teachers and the impacts of the termination of the PNEM program. The results indicate that the training offered to teachers was of significant quality, inducing the recognition of the individuality of students. The termination of the National Pact for Strengthening High School Education was a negative factor, as was the fear of an increased devaluation of teachers under the High School Reforms proposed.
\end{abstract}

Keywords: PNEM. Study Supervisor. Continuing education.

\section{Pacto Nacional para el Fortalecimento de la Escuela Secundaria (PNEM): la formación continuada en Gered de Chapecó - SC}

\section{Resumen}

Este artículo presenta datos sobre la formación continuada de los docentes que ofrece el Pacto Nacional para el Fortalecimiento de la Escuela Secundaria (PNEM) en el periodo 2014-2015. El propósito de este estudio fue investigar las percepciones de los consejeros del estudio sobre la capacitación desarrollada con maestros de 10 escuelas públicas estatales pertenecientes a la Gerencia Regional de Educación (Gered) de Chapecó, al oeste de Santa Catarina. Los datos se obtuvieron a través de una entrevista semiestructurada y sus análisis presentan la opinión del supervisor del estudio, los cambios en las acciones de los docentes y los impactos del fin del PNEM. Los resultados indicaron que la formación fue de una calidad significativa, lo que indujo el reconocimiento del estudiante en su individualidad. Como aspecto negativo, está la finalización del PNEM, así como el temor de aumentar la devaluación de la enseñanza ante la Reforma de la Escuela Secundaria.

Palabras clave: PNEM. Consejero de Estudio. Formación continuada. 


\section{Referências}

ALVARO-PRADA, L. E.; FREITAS, T. C.; FREITAS, C. A. Formação continuada de professores: alguns conceitos, interesses, necessidades e propostas. Revista Diálogo Educacional, Curitiba, v. 10, n. 30, p. 367-387, maio/ago. 2010. https://doi.org/10.7213/rde.v10i30.2464

ARAÚJO, C. M.; ARAÚJO, E. M.; SILVA, R. D. Para pensar sobre a formação continuada de professores é imprescindível uma teoria crítica de formação humana. Cadernos Cedes, Campinas, v. 35, n. 95, p. 57-73, jan./abr. 2015. https://doi.org/10.1590/CC0101-32622015146820

BARDIN, L. Análise de conteúdo. Lisboa: 70, 1979.

BRASIL. Lei ${ }^{\circ}$ 9.394, de 20 de dezembro de 1996. Lei de diretrizes e bases da educação nacional. Diário Oficial da União, Brasília, DF, 23 dez. 1996.

BRASIL. Lei ${ }^{\circ} 13.415$, de 16 de fevereiro de 2017. Altera as leis $\mathrm{n}^{\circ}$ 9.394, de 20 de dezembro de 1996, que estabelece as diretrizes e bases da educação nacional, e 11.494, de 20 de junho 2007, que regulamenta o fundo de manutenção e desenvolvimento da educação básica e de valorização dos profissionais da educação, a consolidação das leis do trabalho - CLT, aprovada pelo Decreto-Lei $\mathrm{n}^{\circ} 5.452$, de 1 de maio de 1943, e o Decreto-Lei $\mathrm{n}^{\circ} 236$, de 28 de fevereiro de 1967; revoga a Lei ${ }^{\circ} 11.161$, de 5 de agosto de 2005; e institui a política de fomento à implementação de escolas de ensino médio em tempo integral. Diário Oficial da União, Brasília, DF, 17 fev. 2017.

BRASIL. Medida Provisória n ${ }^{\circ}$ 746, de 22 de setembro de 2016. Institui a Política de Fomento à Implementação de Escolas de Ensino Médio em Tempo Integral, altera a Lei $\mathrm{n}^{\circ}$ 9.394, de 20 de dezembro de 1996, que estabelece as diretrizes e bases da educação nacional, e a Lei $n^{\circ} 11.494$ de 20 de junho 2007, que regulamenta o Fundo de Manutenção e Desenvolvimento da Educação Básica e de Valorização dos Profissionais da Educação, e dá outras providências. Diário Oficial da União, Brasília, DF, 23 set. 2016b.

BRASIL. Ministério da Educação. Formação de professores do ensino médio: avaliação no ensino médio. Curitiba: Universidade Federal do Paraná, 2013d. (Etapa I, caderno VI.)

BRASIL. Ministério da Educação. Formação de professores do ensino médio: ensino médio e formação humana integral. Curitiba: Universidade Federal do Paraná, 2013b. (Etapa I, caderno I). 
BRASIL. Ministério da Educação. Formação de professores do ensino médio: o currículo do ensino médio, seus sujeitos e o desafio da formação humana integral. Curitiba: Universidade Federal do Paraná, 2013c. (Etapa I, caderno III)

BRASIL. Ministério da Educação. Formação de professores do ensino médio: organização do trabalho pedagógico no ensino médio. Curitiba: Universidade Federal do Paraná, 2014. (Etapa II, caderno I.)

BRASIL. Ministério da Educação. Portaria n ${ }^{\circ} 1.140$, de 22 de novembro de 2013. Institui o pacto nacional pelo fortalecimento do ensino médio e define suas diretrizes gerais, forma, condições e critérios para a concessão de bolsas de estudo e pesquisa no âmbito do ensino médio público, nas redes estaduais e distrital de educação. Diário Oficial da União, Brasília, DF, 9 dez. 2013 a.

BRASIL. Ministério da Educação. Professores do ensino médio em formação: saberes e experiências Chapecó: pacto nacional pelo fortalecimento do ensino médio. Florianópolis: Universidade Federal de Santa Catarina, 2015.

BRASIL. Pacto nacional pelo fortalecimento do ensino médio. Brasília, DF, 2016b. Disponível em: http://pactoensinomedio.mec.gov.br/index. php?option=com_content\&view=article\&id=22. Acesso em: 9 jun. 2016.

CARRANO, P. MP do ensino médio: autoritária na forma e equivocada em conteúdo: nota pública da ANPEd sobre a medida provisória do ensino médio. Anped 40 anos, 23 set. 2016. Disponível em: http://www.anped.org.br/news/nota-publica-da-anped-sobremedida-provisoria-do-ensino-medio. Acesso em: 24 jan. 2017.

CASTILHO, D. Reforma do ensino médio: desmonte na educação e inércia do enfrentamento retórico. Pragmatismo Político, 21 fev. 2017. Disponível em: http://www.pragmatismopolitico.com.br/2017/02/reforma-do-ensino-mediodesmonte-educacao-inercia.html. Acesso em: 11 mar. 2017.

FERREIRA, A. T. B.; ALBUQUERQUE, E. B. C.; WINDLER, E. Programas de educação continuada para professores de alfabetização: conceitos e práticas. Ensaio: Avaliação e Políticas Públicas em Educação, Rio de Janeiro, v. 25, n. 96, p. 609-631, jul./set. 2017. https://doi.org/10.1590/s010440362017002501107

FERREIRA, R. A.; RAMOS, L. O. L. O projeto da MP n ${ }^{\circ}$ 746: entre o discurso e o percurso de um novo ensino médio. Ensaio: Avaliação e Políticas Públicas em Educação, Rio de Janeiro, v. 26, n. 101, p. 1176-1196, out./nov. 2018. https://doi.org/10.1590/s0104-40362018002601295 
FREIRE, P. Educação e mudança. Rio de Janeiro: Paz e Terra, 1979.

FREIRE, P. Pedagogia da autonomia: saberes necessários à prática educativa. São Paulo: Paz e Terra, 1996.

GATTI, B. A.; BARRETO, E. S. S. Professores do Brasil: impasses e desafios. Brasília, DF: Unesco, 2009.

GATTI, B. A.; BARRETO, E. S. S.; ANDRÉ, M. E. D. A. Políticas docentes no Brasil: um estado da arte. Brasília, DF: Unesco, 2011.

LUNA, S. V. Planejamento de pesquisa: uma introdução. São Paulo: EDUC, 1997.

MIZUKAMI, M. G. N. Docência, trajetórias pessoais e desenvolvimento profissional. In: REALI, A. M. M. R.; MIZUKAMI, M. G. N. Formação de professores: tendências atuais. São Carlos: Universidade Federal de São Carlos, 1996. p. 59-89.

MOURA, D. H.; LIMA FILHO, D. L. A reforma do ensino médio: regressão de direitos sociais. Retratos da Escola, Brasília, DF, v. 11, n. 20, p. 109-129, jan./jun. 2017. https://doi.org/10.22420/rde.v11i20.760

NÚÑEZ, I. B.; RAMALHO, B. L. A profissionalização da docência: um olhar a partir da representação de professoras do ensino fundamental. Revista Iberoamericana de Educação, Madri, v. 46, n. 9, p. 1-13, set. 2008. https://doi. org/10.35362/rie4691872

SILVA, E. M. A.; ARAÚJO, C. M. A. Reflexão em Paulo Freire: uma contribuição para a formação continuada de professores. In: COLÓQUIO INTERNACIONAL PAULO FREIRE, 5, 2005, Recife. Anais.[..]. Brasília, DF: Fórum Brasileiro de Economia Solidária, 2005. Disponível em: http://189.28.128.100/nutricao/docs/Enpacs/pesquisaArtigos/reflexao_em_ paulo_freire_2005.pdf. Acesso em: 3 jan. 2016.

SILVA, M. R. Como fica o ensino médio com a reforma: vem aí o ensino médio "líquido". Cedes Notícias, 17 fev. 2017. Disponível em: http://www. cedes.unicamp.br/noticias/668. Acesso em: 11 mar. 2017.

SILVA, M. R.; SHEIBE, L. Reforma do ensino médio: pragmatismo e lógica mercantil. Retratos da Escola, Brasília, DF, v. 11, n. 20, p. 19-31, jan./jun. 2017. https://doi.org/10.22420/rde.v11i20.769 


\section{Informações das Autoras:}

Sandra Maria Zardo Morescho: Doutoranda em Educação pelo Programa de Pós-Graduação em Educação da Universidade de Passo Fundo. Bolsista pelo Programa de Suporte à Pós-Graduação de Instituições Comunitárias de Ensino Superior/Coordenação de Aperfeiçoamento de Pessoal de Nível Superior. Modalidade II. Mestre em Educação pela Universidade Comunitária da Região de Chapecó. Contato: samaza@unochapeco.edu.br.

iD https://orcid.org/0000-0001-9714-1552

Nadir Castilho Delizoicov: Doutora em Educação pela Universidade Federal de Santa Catarina. Professora Colaboradora do Programa de Pós-Graduação em Educação Científica e Tecnológica da mesma universidade. Professora do Programa de Pós-Graduação em Educação da Universidade Comunitária da Região de Chapecó. Contato: ridanc. nadir@gmail.com

iD https://orcid.org/0000-0003-3642-8298 